\title{
Variabilidade espacial e temporal da produtividade de culturas sob sistema plantio direto
}

\author{
Telmo Jorge Carneiro Amado(1), Charles Bolson Pontelli(1), Antônio Luís Santi( ${ }^{(1)}$, João Herbert Moreira Viana ${ }^{(2)}$ \\ e Luciano Augusto de Souza Sulzbach ${ }^{(1)}$
}

\begin{abstract}
(1) Universidade Federal de Santa Maria, Centro de Ciências Rurais, Dep. de Solos, CEP 97105-900 Santa Maria, RS. E-mail: tamado@smail.ufsm.br, cpontelli@baseap.com.br, santial@mail.ufsm.br, lucianosulzbach@terra.com.br (2)Embrapa Milho e Sorgo, Caixa Postal 285, CEP 35701-970 Sete Lagoas, MG. E-mail: jherbertmviana@yahoo.com.br
\end{abstract}

\begin{abstract}
Resumo - O objetivo deste trabalho foi avaliar a variabilidade espacial e temporal da produtividade de soja, milho e trigo, em uma lavoura comercial de 57 ha, não irrigada, manejada há mais de dez anos sob sistema plantio direto, em um Latossolo Vermelho distrófico típico, em Palmeira das Missões, RS. A coleta de dados de produtividade de seis cultivos, entre 2000 e 2005 , foi realizada por colhedora equipada com monitor de produtividade. Análises estatísticas e geoestatísticas foram realizadas a fim de avaliar a variabilidade espacial e a presença de dependência espacial ao longo dos anos. A produtividade da soja, do milho e do trigo alcançada apresenta variabilidade com continuidade espacial, correlacionando-se entre si, ao longo dos anos. Em anos de deficit hídrico, verifica-se aumento da variabilidade espacial da produtividade. A cultura do milho é mais eficiente do que a da soja em detectar a variabilidade espacial da produtividade existente na lavoura.
\end{abstract}

Termos para indexação: Glycine max, Zea mays, Triticum aestivum, agricultura de precisão, mapeamento da produtividade, Latossolo.

\section{Spatial and temporal variability of grain yield under no-tillage cropping system}

\begin{abstract}
The objective of this work was to analyze the spatial and temporal yield variability of soybean, corn and wheat in a 57 ha cropland, without irrigation, under no-till for more than ten years in a Typic Hapludox, located in Palmeira das Missões, RS. Yield data of crops from 2000 to 2005 were collected using a combine equipped with yield monitor. Statistical and geostatistical analysis were performed to monitor the range of the spatial variability and its spatial dependence, as well as its behavior over the years. Soybean, corn and wheat yield present spatial variability, which is maintained over time. In dry years, yield variance coefficient increases compared to wet years. Corn was more efficient than soybean to identify spatial yield variability in the cropland.
\end{abstract}

Index terms: Glycine max, Zea mays, Triticum aestivum, precision agriculture, yield mapping, Oxisol.

\section{Introdução}

O manejo pode conduzir, gradualmente, a uma melhoria da qualidade do solo agrícola até alcançar a excelência expressa por, entre outras propriedades, elevado potencial produtivo. Em sentido oposto, o manejo adotado pode conduzir a um processo de regressão da qualidade do solo até alcançar a degradação, que se expressa por baixas produtividades (Vezzani, 2001).

O sistema plantio direto é uma das mais eficientes estratégias para melhoria da qualidade e do potencial produtivo do solo agrícola. No entanto, esta melhoria não se manifesta de forma homogênea em toda a área. Em uma mesma lavoura é possível encontrar subáreas com diferentes níveis de qualidade e, portanto, com diferentes potenciais produtivos, embora as práticas de manejo adotadas tenham sido aplicadas uniformemente (Amado et al., 2005).

Dampney \& Moore (1999) sugeriram análise do histórico de desenvolvimento das culturas a fim de caracterizar a variabilidade espacial existente na área. Assim, o mapeamento de produtividade, proporcionado pelas ferramentas da agricultura de precisão (AP), destaca-se como alternativa moderna para gerenciar a variabilidade espacial e temporal de lavouras comerciais, orientando práticas de manejo (Molin, 1997; Milani et al., 2006).

Desta maneira, mapas de produtividade podem ser utilizados na investigação das causas da variabilidade, e podem ser um recurso eficaz nas decisões sobre o 
manejo do solo (Molin, 1997; Mantovani, 2006). Milani et al. (2006) relatam que o manejo localizado tendeu a apresentar produtividades mais homogêneas e superiores ao manejo uniforme. Tal aplicação, no entanto, requer acompanhamento e análise de mapas de produtividade, considerando um histórico de várias safras e de diferentes culturas para que sejam contempladas as variabilidades temporal e espacial (Blackmore et al., 2003). Assim, a caracterização da variabilidade na produtividade deve ser feita mediante a investigação de pelo menos três anos de mapeamento (Mantovani, 2006; Santi, 2007). No Brasil, ainda são escassas as áreas que possuem um conjunto de mapas de produtividade que permitam esta análise temporal.

A coleta de dados de produtividade por colhedora deve ser acompanhada de cuidados operacionais, uma vez que fatores como a largura efetiva de corte da plataforma, entrada e saída da lavoura, número de manobras e a limpeza do sensor de rendimento estão entre os mais importantes para a obtenção de dados confiáveis. Sob este aspecto, a cultura do milho apresenta vantagens em relação às demais, pois permite que o operador tenha controle efetivo sobre a largura de corte da plataforma. Já nas culturas da soja e trigo, este controle é dependente da habilidade e atenção do operador, sendo fonte recorrente de erros nos mapas de produtividade. Além disso, o sensor de rendimento, durante a colheita de soja, apresenta maior acúmulo de impurezas e necessita de limpezas freqüentes. Este fato é minimizado na cultura do milho, pela característica da planta e da altura de corte, que diminui a entrada de solo na plataforma (Santi, 2007). Por isso considera-se que o mapa de produtividade da cultura do milho seja mais eficiente para discriminar a variabilidade espacial das lavouras.

A variabilidade espacial e temporal da produtividade foi investigada pela análise de um conjunto de seis mapas de soja, de milho e de trigo, durante cinco anos, em uma área comercial manejada sob sistema plantio direto consolidado no Rio Grande do Sul.

\section{Material e Métodos}

A pesquisa foi realizada em uma área comercial de 57 ha, localizada no Município de Palmeira das Missões, $\mathrm{Km} 15$ da BR-468, situada próximo às coordenadas geográficas datum WGS 84 meridiano central $51^{\circ}$, $27^{\circ} 53^{\prime} \mathrm{S}$ e $51^{\circ} 18^{\prime} \mathrm{W}$, com altitude aproximada de $600 \mathrm{~m}$. Esta é uma das áreas no Rio Grande do Sul pioneiras no emprego de tecnologias da AP, sendo uma base experimental da UFSM.

Essa região situa-se na zona da escarpa arenitobasáltica do Planalto Meridional Brasileiro. O solo é classificado como Latossolo Vermelho distrófico típico, com profundidade média de $1,5 \mathrm{~m}$ e teores de argila de 600 a $750 \mathrm{~g} \mathrm{~kg}^{-1}$. A área vem sendo manejada sob sistema de plantio direto há dez anos, com cultivos de soja e do milho no verão (soja, 2000/2001; milho, 2001/ 2002; soja, 2002/2003; soja, 2003/2004 e milho, 2004/ 2005) alternados com trigo e culturas de cobertura hibernais - aveia-preta, 2000; nabo forrageiro, 2001; trigo, 2002; trigo, 2003 e consórcio aveia-preta + nabo forrageiro + tremoço-azul, 2004 -, obedecendo a um plano de rotação de culturas preestabelecido. A semeadura da soja foi realizada em novembro, a do milho, em setembro, a do trigo, em junho, e as culturas de cobertura, em abril e maio.

O clima da região, segundo a classificação de Köppen, é do tipo Cfa subtropical. A temperatura média normal do mês mais quente ocorre em janeiro $\left(24,6^{\circ} \mathrm{C}\right)$ e a do mês mais frio em junho $\left(12,9^{\circ} \mathrm{C}\right)$. A média normal das máximas é de $30,4^{\circ} \mathrm{C}$, em janeiro, e de $19,2^{\circ} \mathrm{C}$, em junho. A média das temperaturas mínimas do mês mais quente é de $18,7^{\circ} \mathrm{C}$, em dezembro, e de $9,3^{\circ} \mathrm{C}$ a do mês mais frio, em junho. As chuvas são distribuídas regularmente em praticamente todos os meses do ano, sem estação seca definida, com precipitação oscilando entre $1.500 \mathrm{~mm}$ a $1.750 \mathrm{~mm}$. As precipitações, entre $2000 \mathrm{e}$ 2005, foram registradas diariamente pelo pluviômetro instalado na lavoura. Ainda, utilizou-se registro de dados de precipitação mensal do período de 1978 a 2005 da área.

Dados georreferenciados de produtividade das culturas de soja, milho e trigo foram obtidos, desde a safra 2000/2001, com o auxílio de uma colhedora da marca Massey Ferguson, modelo MF 34, equipada com o Sistema Fieldstar, que congrega um conjunto composto de sensor de rendimento do tipo Micro-Trak (MicroTrak Systems Inc.) de duas hastes, cartão para armazenamento de dados tipo PCMCIA e uma antena receptora de sinal com Sistema de Posicionamento Global (GPS).

Inicialmente, nas safras 2000/2001 e 2001/2002, foi utilizado um receptor de DGPS Trimble, Ag 114 (Trimble Navigation Limited), com correção diferencial RACAL. Nos anos seguintes, foi utilizado um receptor de GPS Garmin, Série 35. O sistema foi ajustado para armazenar os dados de posição, latitude, 
longitude e altitude, da máquina e a produção de grãos por unidade de área com intervalo de tempo de $2 \mathrm{~s}$. No Datavision, o tempo de entrada na lavoura foi ajustado para $20 \mathrm{~s}$ e o tempo de saída para $10 \mathrm{~s}$, de modo a compensar o tempo necessário para o fluxo de grãos no interior da colhedora alcançar o sensor de rendimento.

A colhedora utilizada não estava equipada com sensor de umidade de grãos. A fim de reduzir o efeito da variação da umidade dos grãos sobre a qualidade dos mapas de produtividade, procedimentos de campo e de pós-processamento de dados foram adotados.

No campo, durante a colheita, cada grupo de três tanques graneleiros, correspondente a uma carga de caminhão, foi tratado como um arquivo individual no sistema de armazenamento dos dados. Assim, cada carga de caminhão, equivalente a um arquivo individual, foi pesada separadamente, com determinações da umidade e de impureza. Os resultados informados pela cooperativa no boletim de entrada contendo peso bruto, tara do caminhão, peso líquido, impurezas, data e hora de descarga foram utilizados, em campo, para ajustar o fator de correção no Datavision do novo arquivo criado, e no escritório, para correção da umidade e impurezas correspondente ao arquivo.

Desta forma, na área de 57 ha foram gerados, em cada evento de colheita com duração aproximada de três dias, em média 17 arquivos, correspondendo, no pósprocessamento, a uma correção de umidade e impurezas, para cada área de aproximadamente $2,85 \mathrm{ha}$. A colheita sempre foi realizada em nível, de modo a reduzir o efeito da declividade sobre a variabilidade da umidade dos grãos. O sensor de rendimento de grãos foi limpo freqüentemente e os demais procedimentos de calibração recomendados pelo fabricante foram rigorosamente seguidos.

No pós-processamento os dados brutos de produtividade passaram, inicialmente, por uma filtragem a fim de eliminar os erros mais freqüentes durante a colheita, tais como dados coletados durante as manobras nas bordas da lavoura ou em condições estáticas e ajuste de largura de plataforma. Para tanto, os dados brutos, armazenados no formato *.fys, foram exportados para uma planilha eletrônica Microsoft Excel, analisados e os valores de produtividade improvável, devido ao seu muito alto ou muito baixo valor, foram descartados, seguindo método proposto por Menegatti \& Molin (2003). Posteriormente, os dados foram analisados visando excluir informações sobre produtividade com erros de posicionamento (coordenadas repetidas) e entrada e saída da lavoura, tempo de enchimento e de esvaziamento da máquina. Essa filtragem consistiu na eliminação dos dados armazenados equivalentes a cinco leituras, no início e no fim de cada manobra realizada nas extremidades da lavoura (Moore, 1998; Menegatti \& Molin, 2003). Aproximadamente 5\% dos dados brutos foram descartados no processo de filtragem.

No pós-processamento dos dados, foram corrigidos os valores de umidade e impurezas. Para tanto, utilizaram-se informações contidas no boletim de entrada de carga na cooperativa; cada arquivo foi corrigido individualmente, distribuindo-se linearmente a umidade e a impureza correspondente. Desta forma, o peso total de grãos de cada arquivo foi ajustado ao valor registrado na cooperativa. Os resultados de produtividade das três culturas investigadas foram então padronizados para $13 \%$ de umidade.

Com o programa Campeiro 5 - AV3 (Giotto et al., 2004) -, foram geradas grades com 2.533 quadrículas. Cada quadrícula representou uma célula de $15 \times 15 \mathrm{~m}$. Nessas células, utilizou-se um raio de busca de $20 \mathrm{~m}$ para gerar a média dos valores de produtividade registrados. Por meio de uma das ferramentas, análise por células, disponíveis no programa citado, foi calculada a razão entre a produtividade da célula e a média de produtividade da área na safra, expressando o resultado em porcentagem. Assim, foi possível normalizar a produtividade e comparar diferentes culturas e safras sempre com a mesma localização espacial.

Quanto ao estudo da variabilidade espacial e temporal, três classes de produtividade foram consideradas, segundo os critérios propostos por Molin (2002). As produtividades com valores superiores a $105 \% \mathrm{em}$ relação à média geral de produtividade da área constituíram a classe de alta produtividade, as produtividades entre 95 e $105 \%$ constituíram a classe de média produtividade e as inferiores a $95 \%$, a classe de baixa produtividade.

Os mapas de produtividade foram interpolados, utilizando-se o inverso do quadrado da distância com raio de $15 \mathrm{~m} \mathrm{e}$, posteriormente, sobrepostos gerando um único mapa representativo de todas as culturas e safras investigadas, possibilitando a análise temporal.

A análise estatística descritiva exploratória e das correlações entre os seis conjuntos de dados de produtividade, pela matriz de correlação de Pearson, foi 
realizada utilizando-se o programa Geovisual (Yamamoto, 2002). A dependência espacial foi investigada com o auxílio de semivariogramas experimentais. $\mathrm{Na}$ análise da dependência espacial dos valores de produtividade de diferentes anos, seguiu-se o método descrito por Goovaerts (1999). Calcularam-se os semivariogramas em várias direções, por tentativa, e selecionaram-se as direções que apresentaram os semivariogramas claramente definidos e, na presença de anisotropia, utilizaram-se as direções norte e noroeste.

$\mathrm{O}$ ajuste dos modelos aos semivariogramas experimentais foi efetuado manualmente, com base em inspeção visual e no resultado da validação cruzada. Foram utilizados, entre os modelos disponíveis no programa (modelos esférico, exponencial, gaussiano e pepita puro), os que apresentavam melhor resultado no teste de validação cruzada. $\mathrm{O}$ programa permite o ajuste de anisotropia geométrica e zonal por meio do uso de modelos de duas estruturas.

\section{Resultados e Discussão}

Os mapas de produtividade são considerados como a alternativa mais completa para discriminar a variabilidade espacial das lavouras (Molin, 2002). No entanto, a geração de mapas de produtividade confiáveis exige cuidados operacionais e de tratamento dos dados.

A importância do registro de umidade dos grãos na qualidade dos mapas de produtividade foi anteriormente destacada por Pierce et al. (1997). Estes autores relataram que a cultura do milho, na mesma lavoura e no mesmo dia de colheita, apresentou variação de 10 a $15 \%$ no teor de umidade. Quanto à soja e ao trigo, os autores sustentaram que a variabilidade espacial da umidade está mais associada às condições climáticas do que a características fisiológicas da cultura. Neste trabalho, desde as primeiras safras foi possível constatar, no mesmo dia de colheita, a existência de variação na umidade dos grãos, associando-se este fato ao relevo da área, a variabilidade espacial da umidade do solo e a cerração nas áreas mais baixas. Os valores de umidade, no mesmo dia de colheita, variaram entre 2,5 a 7,5\%. Já a variação da porcentagem das impurezas foi menor, variando de 1 a $2 \%$. Por isso, desenvolveu-se um método específico de campo e de pós-processamento de dados, que visava corrigir, a cada dia de colheita, entre sete e oito vezes o valor de umidade. Este método, embora não tenha eliminado todos os erros induzidos pela ausência de sensor de umidade, reduziu a incerteza das medições de produtividade, melhorando a qualidade dos mapas de produtividade.

A produtividade das culturas de grãos, de 2000 a 2005, apresentou variabilidade espacial e temporal, com coeficiente de variação entre 12 e $27 \%$ (Tabela 1), semelhante ao encontrado por Milani et al. (2006). Portanto, nenhuma safra apresentou coeficiente de variação baixo $(<10 \%)$ e duas safras apresentaram coeficiente de variação alto $(>20 \%)$, segundo a classificação proposta por Pimentel-Gomes (1984). Nas culturas da soja e do milho, as maiores produtividades médias, nos três primeiros anos, podem ser justificadas pela adequada disponibilidade hídrica (Figura 1). Por sua vez, durante o ciclo da soja, safra 2003/2004, e do milho, safra 2004/2005, foram observados, em fevereiro e março, valores de precipitação muito inferiores à média (Figura 1), fato que resultou na elevação do coeficiente de variação e reduções da produtividade média em, aproximadamente, 30 e $25 \%$, respectivamente (Tabela 1).

O quartil superior, por abranger um conjunto de dados, está menos sujeito a erros do que valores isolados como os da produtividade máxima. Os valores de quartil superior foram $3.632,3.925$ e $8.940 \mathrm{~kg} \mathrm{ha}^{-1}$, para soja, trigo e milho, respectivamente. As produtividades alcançadas, nesta lavoura, estão de acordo com a tecnologia e as práticas

Tabela 1. Parâmetros estatísticos descritivos dos dados de produtividade das culturas de soja, milho e trigo, em seis safras.

\begin{tabular}{lcccrrr}
\hline Variáveis & Soja & Milho & Soja & Trigo & Soja & Milho \\
& $2000 / 2001$ & $2001 / 2002$ & $2002 / 2003$ & 2003 & $2003 / 2004$ & $2004 / 2005$ \\
\hline Média (kg) & 3.186 & 7.845 & 3.314 & 3.512 & 2.238 & 5.990 \\
Desvio-padrão (kg) & 412 & 1.444 & 600 & 561 & 540 & 1.637 \\
CV (\%) & 12,0 & 18,0 & 18,0 & 16,0 & 24,0 & 27,0 \\
Máximo (kg) & 4.453 & 12.397 & 5.897 & 5.116 & 3.688 & 15.643 \\
Quartil superior (kg) & 3.463 & 8.940 & 3.632 & 3.925 & 2.643 & 6.732 \\
Mediana (kg) & 3.209 & 7.984 & 3.281 & 3.586 & 2.210 & 5.838 \\
Quartil inferior (kg) & 2.904 & 6.804 & 2.927 & 3.160 & 1.835 & 5.005 \\
Mínimo (kg) & 2.034 & 3.331 & 1.801 & 1.428 & 764 & 1.701 \\
\hline
\end{tabular}



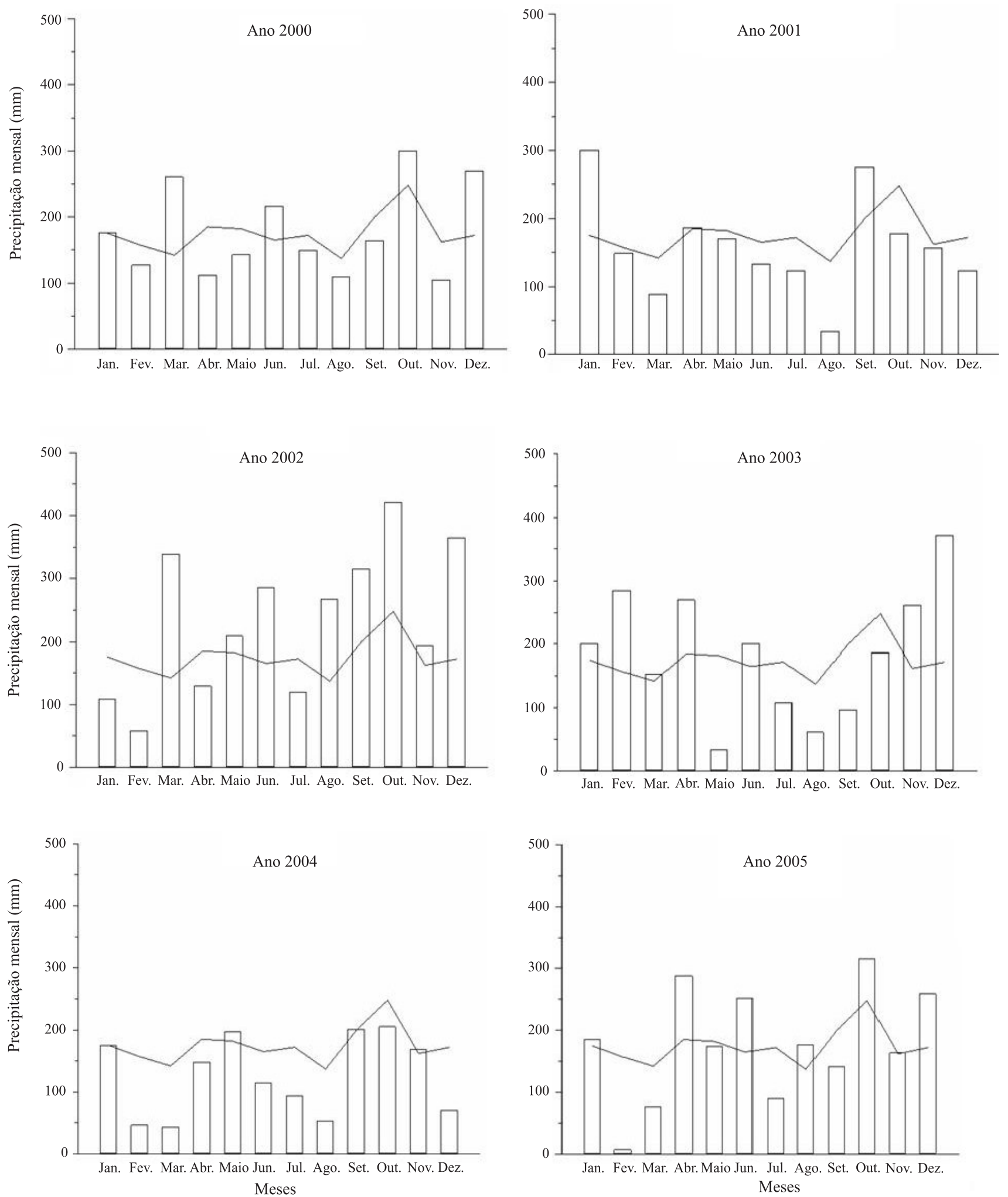

Figura 1. Precipitações mensais ocorridas durante os seis anos de avaliação e precipitação média (—)de 1978 a 2005 . Palmeira das Missões, RS. 
de manejo adotadas. Os valores de quartil superior e inferior da soja se aproximam do anteriormente encontrado por Milani et al. (2006) em Cascavel, Paraná.

A partir da produtividade média da soja na safra de 2002/2003, ano com precipitação normal, observa-se que o rendimento relativo dos demais anos foi de 96 e $67 \%$, respectivamente, nas safras de 2000/2001 e 2003/2004. Assim, ainda considerando-se como referência a safra $2002 / 2003$, verifica-se decréscimos no quartil superior de 6 e $28 \%$, respectivamente, nas safras 2000/2001 e 2003/ 2004 (Tabela 1). Em contrapartida, para o quartil inferior, os decréscimos foram de 1 e $38 \%$, respectivamente. Portanto, neste caso, o quartil inferior foi o que apresentou a maior perda relativa da produtividade no ano com deficit hídrico. Este resultado sugere que zonas de baixo potencial produtivo de soja são as mais sensíveis ao estresse ambiental. No entanto, no milho o decréscimo de produtividade ocorreu de forma uniforme.

A soja, em anos de precipitação normal, apresentou desenvolvimento que tendeu à homogeneidade na área. Por sua vez, em anos com restrição hídrica, a diferença de produtividade entre as zonas de produtividade foi mais acentuada. Por exemplo, nas safras com precipitação normal, o rendimento do quartil inferior foi de 81 e $84 \%$ em relação ao quartil superior, enquanto no ano com deficit hídrico foi de $69 \%$. No milho, a relação quartil inferior/ superior foi de $76 \%$ (ano normal) e 74\% (ano com deficiência hídrica), portanto essa cultura apresentou eficiência semelhante, entre os anos, em discriminar zonas com diferentes potenciais produtivos.

No Rio Grande do Sul, a instabilidade climática influencia acentuadamente a variabilidade temporal da produtividade das culturas (Berlato et al., 2005). Este fato também foi observado neste trabalho, cujas produtividades no quartil superior da soja e do milho, nos anos de deficit hídrico (2003/2004 e 2004/2005), foram menores do que as produtividades no quartil inferior dos anos com precipitação normal (2002/2003).
Quanto ao coeficiente de variação, os maiores valores foram observados nas safras que apresentaram estiagem (Tabela 1). Este fato, provavelmente, está associado às propriedades físicas do solo da área em estudo. Amado et al. (2005) e Santi (2007), nesta mesma área, encontraram indicativos de compactação do solo e limitação à infiltração de água nas zonas que, ao longo dos anos, têm apresentado baixas produtividades. Com isto, deduz-se que as restrições ao desenvolvimento radicular e à permeabilidade do solo, observados nas zonas de baixo potencial produtivo, agravaram o efeito do deficit hídrico.

As correlações entre as produtividades das culturas foram altamente significativas na maioria das safras investigadas (Tabela 2). A correlação entre os mapas de produtividade intraculturas variou de 0,17 a 0,40 na soja e foi de 0,34 no milho. Na investigação da correlação interculturas, observou-se correlação de 0,50 entre a cultura do trigo (safra 2003) e a cultura do milho (safra 2001/2002), para uma condição de safras com precipitação normal, e correlação não-significativa $(-0,09)$, para uma condição com deficit hídrico (2004/2005). Portanto, neste caso, o efeito do clima aparentemente foi o fator que influenciou de maneira mais marcante a correlação entre a produtividade destas duas culturas. A cultura do trigo, quando correlacionada com a soja, apresentou valores de $0,33,0,28$ e 0,56 nas safras de 2000/2001, 2002/2003 e 2003/2004, respectivamente.

A correlação da soja na safra referência (precipitação normal) com as demais safras apresentou valores de 0,17 , $0,25,0,28$ e 0,25 , respectivamente, nas culturas da soja 2000/2001, milho 2001/2002, trigo 2003 e soja 2003/2004 (Tabela 2). Por sua vez, na soja, em safra com deficit hídrico (2003/2004), foram observados os valores mais elevados de correlações $(0,49$ e 0,56$)$ com as culturas de milho e trigo, essas em safras com disponibilidade hídrica adequada. Portanto, infere-se que a soja, por ser mais rústica, somente em situação de estresse ambiental

Tabela 2. Coeficientes de correlação entre a produtividade das culturas da soja, milho e trigo no período de 2000 a 2005.

\begin{tabular}{|c|c|c|c|c|c|c|}
\hline Cultura/safra & $\begin{array}{c}\text { Soja } \\
2000 / 2001\end{array}$ & $\begin{array}{c}\text { Milho } \\
2001 / 2002\end{array}$ & $\begin{array}{c}\text { Soja } \\
2002 / 2003\end{array}$ & $\begin{array}{l}\text { Trigo } \\
2003\end{array}$ & $\begin{array}{c}\text { Soja } \\
2003 / 2004\end{array}$ & $\begin{array}{c}\text { Milho } \\
2004 / 2005\end{array}$ \\
\hline Soja 2000/2001 & 1,00 & & & & & \\
\hline Milho 2001/2002 & $0,29 * *$ & 1,00 & & & & \\
\hline Soja 2002/2003 & $0,17 * *$ & $0,25 * *$ & 1,00 & & & \\
\hline Trigo 2003 & $0,33 * *$ & $0,50 * *$ & $0,28 * *$ & 1,00 & & \\
\hline Soja 2003/2004 & $0,40 * *$ & $0,49 * *$ & $0,25 * *$ & $0,56 * *$ & 1,00 & \\
\hline Milho 2004/2005 & $0,12 * *$ & $0,34 * *$ & $-0,01^{\mathrm{ns}}$ & $0,09^{\mathrm{ns}}$ & $0,25 * *$ & 1,00 \\
\hline
\end{tabular}

(1)ns Não-significativo. **Significativo a $1 \%$ de probabilidade. 
discrimina eficientemente as diferenças de qualidade do solo detectadas pelas demais culturas (milho e trigo). Molin (2002), ao avaliar um conjunto de quatro safras de culturas de grãos, em São Paulo, também concluiu que o milho apresentou maior estabilidade na variabilidade espacial do que a soja.

Blackmore et al. (2003), ao analisar mapas de produtividade de seis anos, observaram variabilidade espacial aleatória da produtividade nas áreas de estudo, sugerindo possíveis compensações de acordo com variações climáticas entre os anos. Neste trabalho observou-se que a área investigada apresentou continuidade espacial da produtividade, descrita por semivariogramas estruturados (Figura 2), em que as diferentes classes de produtividade se repetem ao longo dos anos. Com isto, justifica-se a utilização dos mapas de rendimento como ferramenta para decisões referentes a manejo localizado.
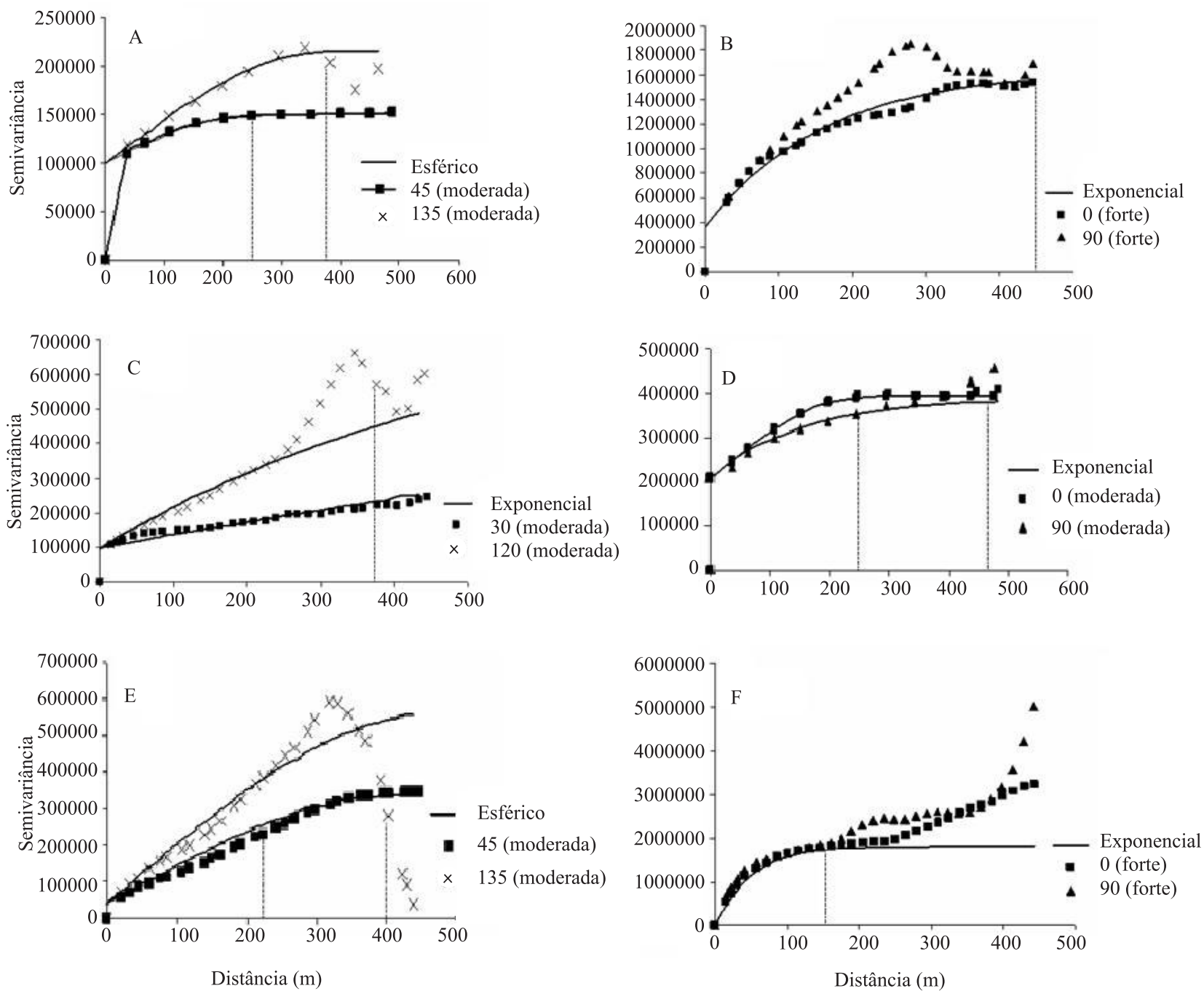

Figura 2. Semivariogramas experimentais da produtividade das culturas: A) comportamento anisotrópico da soja 2000/2001; B) comportamento anisotrópico do milho 2001/2002; C) comportamento isotrópico do trigo 2003; D) comportamento anisotrópico da soja 2002/2003; E) comportamento anisotrópico da soja 2003/2004; F) comportamento isotrópico do milho 2004/2005; (---) alcance. Relação dependência espacial (forte $\leq 25 \%$; moderada 26 a $75 \%$; fraco $\geq 75$ a $100 \%$ e efeito pepita puro $\geq 100 \%$ ) segundo classificação proposta por Cambardella et al. (1994). Palmeira das Missões, RS. 
A variabilidade espacial das produtividades das culturas expressou dependência espacial classificada como moderada a forte, segundo o proposto por Cambardella et al. (1994), com valores de alcance que variaram de 154 a 798 m (Figura 2). A dependência espacial foi semelhante à encontrada por Milani et al. (2006). O alcance é importante para a interpretação dos semivariogramas, por indicar a distância até onde os pontos amostrais estão correlacionados entre si, ou seja, os pontos localizados em uma área cujo raio seja o alcance, são mais semelhantes entre si, do que os separados por distâncias maiores (Vieira et al., 1983; Carvalho et al., 2002). Para garantir a dependência espacial, os pontos de amostragem deveriam ser coletados a uma distância equivalente à metade do alcance (Carvalho et al., 2002). Com base neste critério pode-se deduzir que a distância de coleta de pontos amostrais proporcionada pela colhedora foi muito inferior à metade do alcance calculado (Figura 2), garantindo a dependência espacial.

As culturas do milho e do trigo apresentaram dependência espacial classificada como forte (efeito pepita $\leq 25 \%$ do patamar), exceção do trigo na direção de $120^{\circ}$, ao passo que para a soja, a dependência espacial foi moderada (efeito pepita entre 26 e $75 \%$ do patamar). A dependência espacial do milho foi semelhante à encontrada anteriormente por Rodrigues (2002), e a da soja semelhante à faixa de valores de 17,3 a $60,4 \%$ encontrada por Milani et al. (2006).

As direções dos semivariogramas coincidem, aproximadamente, com as direções de maior declividade do terreno e, neste caso, a diferença na produtividade pode estar associada à fatores topográficos locais, como áreas mais erodidas localizadas nas partes mais baixas, a norte e a noroeste do terreno conforme apresentado na Figura 3, na qual os seis mapas de rendimento foram normalizados e sobrepostos.

A técnica de validação cruzada, segundo Isaaks \& Sirivastava (1989), pode ser usada para testar o modelo ajustado ao semivariograma, isto é, testar o modelo para valores reais. A técnica consiste em retirar um valor real do banco de dados e estimá-lo usando o modelo variográfico. A validação é realizada comparando os valores estimados com os valores reais, usando a regressão linear como critério de comparação. Nas Figuras 2 e 4 são apresentados, respectivamente, os semivariogramas e os gráficos de correlação entre valores observados e estimados pelos modelos. De modo geral, os valores de correlação foram satisfatórios (Figura 4). Quanto à cultura da soja, observou-se, nos dois primeiros anos de cultivo, que os modelos apresentaram menor ajuste aos dados de campo com coeficiente de correlação de 0,60 e 0,62 , respectivamente, nas safras 2000/2001 e 2002/2003 (Figura 4 A e D). Na safra 2003/2004, obteve-se melhor ajuste do modelo aos dados, e o coeficiente de correlação, na validação cruzada, foi de 0,88 (Figura 4 E). Milani et al. (2006) encontraram modelos exponencial e esférico ajustados aos semivariogramas da soja, assim como o verificado neste trabalho (Figura 2). Na cultura do trigo, essa correlação foi de 0,75 (Figura 4 C) e, no milho, foi de 0,85 e 0,88 (Figura 4 B e E) para as safras 2001/2002 e $2004 / 2005$.

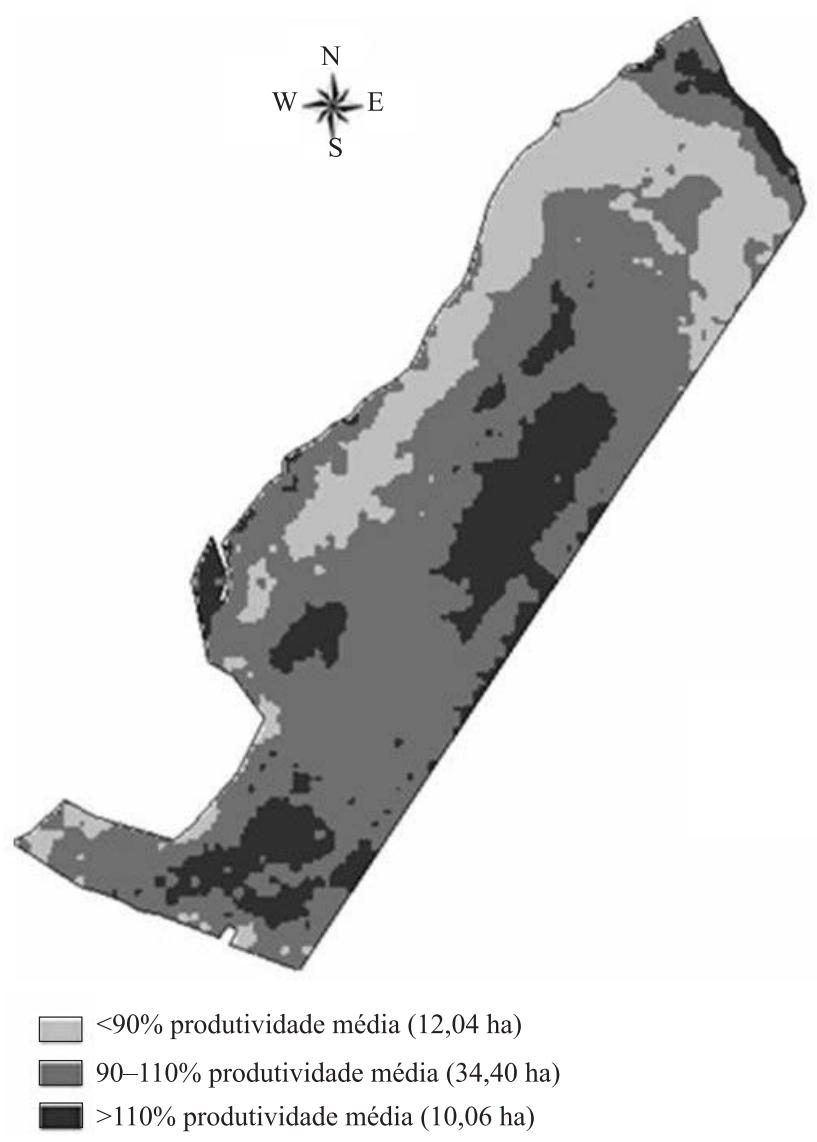

Figura 3. Distribuição espacial da produtividade de grãos das culturas das seis safras. 

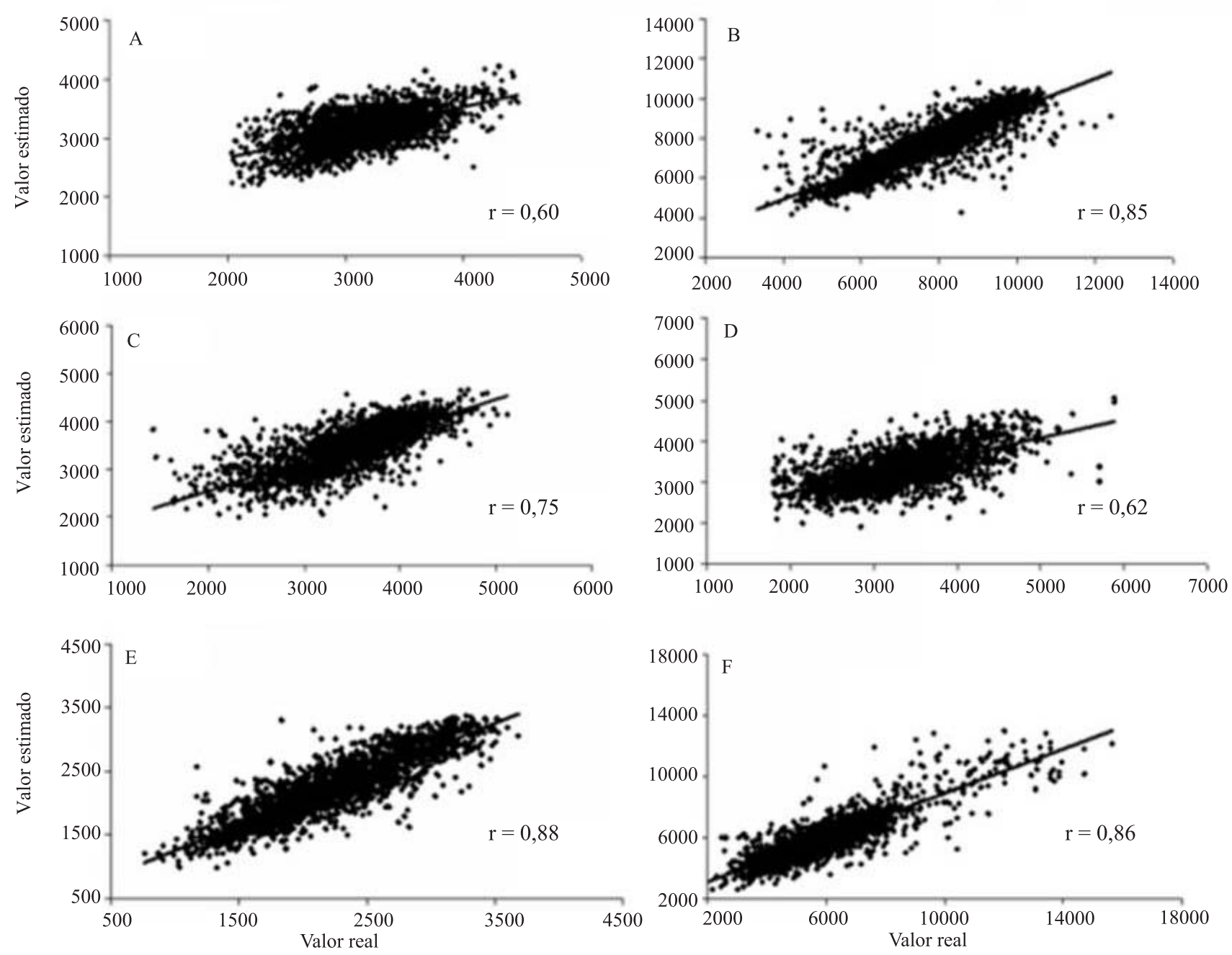

Figura 4. Gráfico da validação cruzada da produtividade: A) soja 2000/2001; B) milho 2001/2002; C) trigo 2003; D) soja 2002/ 2003; E) soja 2003/2004; F) milho 2004/2005.

\section{Conclusões}

1. A área sob sistema plantio direto consolidado apresenta existência de variabilidade com continuidade espacial de produtividade, descrita por semivariogramas estruturados; as produtividades de soja, de milho e de trigo geralmente estão correlacionadas entre si nas diferentes safras.

2. Em anos com ocorrência de deficit hídrico, há aumento da variabilidade espacial da produtividade; as zonas classificadas como de baixo potencial produtivo apresentam os maiores decréscimos relativos de produtividade da soja.
3. A produtividade da cultura da soja apresenta dependência espacial classificada como moderada e, em anos com precipitação normal, restrita capacidade de discriminar a variabilidade espacial existente na lavoura; a produtividade da cultura do milho apresenta dependência espacial classificada como forte e é mais eficiente na descrição da variabilidade espacial existente na lavoura.

\section{Agradecimentos}

À família Sulzbach, pela colaboração e cessão da área experimental; ao CNPq, Fapergs, Agrisus, Manah e AGCO, pelo suporte financeiro. 


\section{Referências}

AMADO, T.J.C.; NICOLOSO, R.; LANZANOVA, M.; SANTI, A.L.; LOVATO, T. A compactação pode comprometer os rendimentos de áreas sob plantio direto. Revista Plantio Direto, n.89, p.34-42, 2005.

BERLATO, M.A.; FARENZENA, H.; FONTANA, D.C. Associação entre El Nino Oscilação Sul e a produtividade do milho no Estado do Rio Grande do Sul. Pesquisa Agropecuária Brasileira, v.39, p.423-432, 2005.

BLACKMORE, B.S.; GODWIN, R.J.; FOUNTAS, S. The analysis of spatial and temporal trends in yield map data over six years. Biosystems Engineering, v.84, p.455-466, 2003.

CAMBARDELLA, C.A.; MOORMAN, T.B.; NOVAK, J.M.; PARKIN, T.B.; KARLEN, D.L.; TURCO, R.F.; KONOPKA, A.E. Field-scale variability of soil properties in Central Iowa soils. Soil Science Society of American Journal, v.58, p.1501-1511, 1994.

CARVALHO, J.R.P.; SILVEIRA, P.M.; VIEIRA, S.R. Geoestatística na determinação da variabilidade espacial de características químicas do solo sob diferentes preparos. Pesquisa Agropecuária Brasileira, v.37, p.1151-1159, 2002.

DAMPNEY, P.M.R.; MOORE, M. Precision agriculture in England: current practice and research-based advice to farmers. In: INTERNATIONAL CONFERENCE ON PRECISION AGRICUlTURE, 4., 1998, St. Paul. Proceedings. Madison: American Society of Agronomy, 1999. p.661-673.

GIOTTO, A.; ROBAINA, A.D.; SULZBACH, L. Agricultura de precisão com o sistema CR Campeiro5. Santa Maria: [s.n.], 2004. 330p.

GOOVAERTS, P. Geostatistics in soil science: state-of-the-art and perspectives. Geoderma, v.89, p.1-45, 1999.

ISAAKS, E.H.; SIRIVASTAVA, M. Introduction to applied geostatistics. New York: O0xford University Press, 1989. 561p.

MANTOVANI, E.C. Agricultura de precisão na Embrapa. Brasília: [s.n.], 2006. 8p. Disponível em: http://www.ripa.com.br/ fileadmin/user_upload/_temp_/Projeto_Agricultura_de_PrecisaoJunho_2006.doc. Acesso em: 9 jul. 2007.
MENEGATTI, L.A.A.; MOLIN, J.P. Remoção de erros em mapas de produtividade via filtragem de dados brutos. Revista Brasileira de Engenharia Agrícola e Ambiental, v.8, p.126-134, 2004.

MILANI, L.; SOUZA, E.G. de; URIBE-OPAZO, M.A.; GABRIEL FILHO, A.; JOHANN, J.A.; PEREIRA, J.O. Unidades de manejo a partir de dados de produtividade. Acta Scientiarum Agronomy, v.28, p.591-598, 2006.

MOLIN, J.P. Agricultura de precisão, parte I: o que é e estado da arte em sensoriamento. Engenharia Agrícola, v.17, p.97-107, 1997.

MOLIN, J.P. Definição de unidades de manejo a partir de mapas de produtividade. Engenharia Agrícola, v.22, p.83-92, 2002.

MOORE, M. An investigation into the accuracy of yield maps and their subsequent use in crop management. 1998. 379p. Thesis (Ph.D.) - Cranfield University, Warwick.

PIERCE, F.J.; ANDERSON, N.W.; COLVIN, T.S.; SCHUELLER, J.K.; HUMBURG, D.S.; McLAUGHLIN, N.B. Yield mapping. In: The site-specific management for agricultural systems. Madison: ASA-CSSA-SSSA, 1997. p.211-243.

PIMENTEL-GOMES, F. A estatística moderna na pesquisa agropecuária. Piracicaba: Associação Brasileira para Pesquisa da Potassa e do Fosfato, 1984. 160p.

RODRIGUES, J.B.T. Variabilidade espacial e correlações entre atributos de solo e produtividade na agricultura de precisão. 2002. 126p. Tese (Mestrado) - Universidade Estadual de São Paulo, Botucatu.

SANTI, A.L. Relações entre indicadores de qualidade do solo e a produtividade das culturas em áreas com agricultura de precisão. 2007. 150p. Tese (Doutorado) - Universidade Federal de Santa Maria, Santa Maria.

VEZZANI, F.M. Qualidade do sistema solo na produção agrícola. 2001. 143p. Tese (Doutorado) - Universidade Federal do Rio Grande do Sul, Porto Alegre.

VIEIRA, S.R.; HATFIELD, J.L.; NIELSEN, D.R.; BIGGAR, J.W. Geostatistical theory and application to variability of some agronomical properties. Hilgardia, v.51, p.1-75, 1983.

YAMAMOTO, J.K. Sistema Geovisual 2.2: guia do usuário. São Paulo: Instituto de Geociências da USP, 2002. 82p.

Recebido em 7 de novembro de 2006 e aprovado em 10 de julho de 2007 